\title{
Numerical simulation of rainfall and temperature over Kenya using Weather Research and Forecasting-Environmental Modelling System (WRF-EMS)
}

\author{
Philip Obaigwa Sagero ${ }^{\mathrm{A}, \mathrm{D}^{*}}$, Chris Shisanya ${ }^{\mathrm{A}}$, Victor Ongoma $^{\mathrm{B}, \mathrm{C}}$, Zablon Weku Shilenje ${ }^{\mathrm{D}}$ \\ Received: December 9, 2015 | Revised: March 7, 2016 | Accepted: June 1, 2016 \\ DOI: 10.18421/GP20.02-01
}

\begin{abstract}
This paper focuses on one of the high resolution models used for weather forecasting at Kenya Meteorological Department (KMD). It reviews the skill and accuracy of the Weather Research and Forecasting (WRF) - Environmental Modeling System (EMS) model, in simulating weather over Kenya. The study period was March to May 2011, during the rainy season over Kenya. The model output was compared with the observed data from 27 synoptic stations spread over the study area, to determine the performance of the model in terms of its skill and accuracy in forecasting. The spatial distribution of rainfall and temperature showed that the WRF model was capable of reproducing the observed general pattern especially for temperature. The model has skill in forecasting both rainfall and temperature over the study area. However, the model may underestimate rainfall of more than $10 \mathrm{~mm} /$ day and displace its location and overestimate rainfall of less than $1 \mathrm{~mm} /$ day. Therefore, during the period of enhanced rainfall especially in the month of April and part of May the model forecast needs to be complemented by other models or forecasting methods before giving a forecast. There is need to improve its performance over the domain through review of the parameterization of small scale physical processes and more observed data need to be simulated into the model.
\end{abstract}

Keywords: rainfall, temperature, weather forecasting, WRF, Kenya

\section{Introduction}

Rainfall is the most important weather parameter in Kenya, and many other developing nations whose economy mainly depend on rain-fed agriculture (Muthama, et al., 2012). Extreme weather events are thus associated with huge socio-economic losses that can be avoided through provision of accurate and timely weather forecast. The effects of severe weather are localized in most cases, calling for skillful forecast. However, the utility of the forecast depend on the skill of the model. There exist different weather forecasting models that perform differently from one locality to the other. This study assesses the performance of the Weather Research and Forecasting model (WRF) to simulate weather over Kenya, focusing on temperature and rainfall. The main question to answer is, how well does WRF-EMS model accurately predict severe weather over Kenya? Research on performance of models in weather prediction on daily, monthly and seasonal timescales has been the subject of many studies in East Africa Region, includ-

\footnotetext{
A Department of Geography, Kenyatta University, P.O Box 43844-00100, Nairobi, Kenya

B College of Atmospheric Sciences, Nanjing University of Information Science and Technology, Nanjing, Jiangsu, 210044, P.R. China

C Department of Meteorology, South Eastern Kenya University, P.O. Box 170-90200, Kitui, Kenya

D Kenya Meteorological Department, P.O. Box 30259-00100, Nairobi, Kenya

* Corresponding author: Philip Obaigwa Sagero, e-mail: psagero@meteo.go.ke, phsagero@gmail.com
} 
ing Kenya. However, the WRF-EMS model has not received adequate attention from researchers, particularly in East Africa region. This may be because the model is used mainly for research rather than operational purposes in the region.

Observed tropical weather is the sum total of nonlinear interactions among quasi-stationary systems like the Inter-Tropical Convergence Zone (ITCZ), depressions, anticyclones, and Hadley wind regimes; systems with low and high frequency variability including the Indian Ocean Dipole (IOD), El-Niño Southern Oscillation (ENSO), tropical cyclones and Madden Julian Oscillations (MJOs); highly seasonal systems like monsoons (Mukabana, 1992); and local forcing from the influence of lakes, orographic features and urban complexes (Asnani, Kinuthia 1979). The challenge of dynamical forecasting lies, not only in precisely incorporating all relevant weather controls in the modelling system, but also in the opposite interpretation of NWP products.

WRF has been used to simulate tornado over Ludhiana in India, the model was able to simulate well all the favorable conditions for formation of a tornado (Mohantya, Litta, 2010). This shows that high resolution model can be reliably used for foresting highly localized systems.

Despite the high-speed computers, inaccurate weather forecasts still being made due to errors from the chaotic nature of the atmosphere, the inexact equations of motions, and gaps in specifying the initial state of the atmosphere. Lilly (1990) studied Numerical Weather Prediction (NWP) and found that at high resolution, convection is explicitly resolved, meaning that clouds and precipitation are entirely represented through additional prognostic equations which account for the microphysical and thermo dynamical transformations associated with water phase changes. Moreover, high resolution allows for a much more detailed representation of the orographic forcing known to play a major role at the mesoscale. There have been efforts in recent days to improve the accuracy of the forecasts, through the use of mesoscale model with high horizontal and vertical resolutions. This is because rainfall can only be predicted with accuracy using fine grid models.

Another major hurdle for mesoscale modeling is the verification of the direct model output against the observed. Observed data for small-scale weather phenomena are either not available, unevenly distributed, or provide incomplete coverage. According to Cherubini et al. (2002), the information contained in the observations may not give the same information as the model without some preconditioning.

Previous model validation studies have used conventional statistics to measure the similarity between observed and modeled data. Taylor (2001) characterized model performance using correlation, root mean square error (RMSE), and variance ratio. The study found ways to combine these three statistics in a single diagram, resulting in nice graphical visualizations of model performance. Murphy, et al. (2004) introduced a Climate Prediction Index (CPI), which measures the reliability of a model based on the composite mean square errors of a broad range of climate variables.

Gitutu (2006) did a comparative verification of precipitation forecast over Kenya. He found out that the skill of the NWP model considered was high during the drier months as compared to the rainy season of March- May. He also noted that during the heavy precipitation the models under consideration under forecasted. Sakwa (2006), also assessed the skill of the High Resolution Regional Model (HRM) in simulation of airflow and rainfall over East Africa, found that the model was able to simulate precipitation and airflow skillfully over East Africa with few cases of underestimation and overestimation.

Over East Africa, and especially Kenya few studies have been carried out on the performance of the WRF model. Zhang (2007) utilized the model and showed it could satisfactory simulate East Africa climate. It is in this background that this study analyses the skill and accuracy of WRF-EMS model over Kenya.

\section{Study area}

The area of focus for this study is Kenya, which lies within longitudes $34^{\circ} \mathrm{E}-42^{\circ} \mathrm{E}$, and latitudes $5^{\circ} \mathrm{N}-5^{\circ} \mathrm{S}$ (Figure 1) with a total area of about $582650 \mathrm{~km}^{2}$. The country is positioned in East Africa bordering Somalia to the east, Ethiopia to the north, Tanzania to the south, Uganda and Lake Victoria to the west, South Sudan to the North West, and the Indian Ocean to the southeast. The equator passes through the country in an east-west direction dividing the country into almost two equal parts.

The region has complex topographical features, which include the highlands and Great Rift Valley. The relief map of Kenya indicates that quite a large portion of the area lies around $1200 \mathrm{~m}$ above mean sea level (AMSL). Climate in Kenya vary considerably from place to place due to differences in topography and the presence of water bodies such as the Indian Ocean and Lake Victoria (Indeje, et al., 2001). Precipitation is the parameter that has the highest space-time variability. On average, more than $800 \mathrm{~mm}$ of annual rainfall is observed over areas bordering Lake Victoria to the west, and the Indian Ocean to the east. The highlands of central Kenya also receive rainfall of more than $800 \mathrm{~mm}$ per year, with the northern and 
(a)

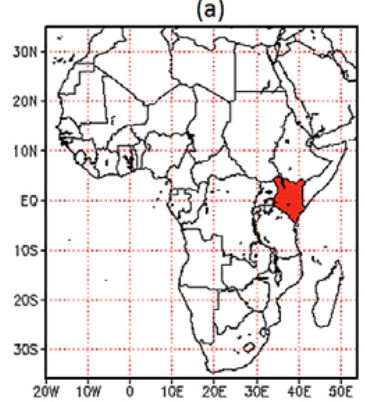

(b)

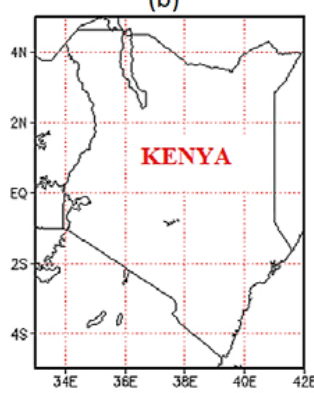

Figure 1. Area of study, (a) Map of Africa showing the Kenya (shaded grey), (b) Map of Kenya [longitude $34^{\circ} \mathrm{E}-$ $42^{\circ} \mathrm{E}$ and latidue $5^{\circ} \mathrm{S}-5^{\circ} \mathrm{N}$ ]

eastern parts of Kenya, which is semi-arid, receive less rainfall.

Kenya experiences bimodal rainfall regime with the 'long rains' season coming in March-May (MAM) and the 'short rains' being reported in September-December (SOND) (Yang, et al., 2015; Camberlin, Philippon 2002; Mutai, Ward 2000; Ogwang, et al., 2015). These rainy season coincide with period of the year when the ITCZ is overhead at the equator (Anyah, Semazzi 2006; Black, et al., 2003). The intervening periods are relatively dry. However, there are rainfall-enhancing mechanisms in the region which contribute to substantial rains over the western and coastal parts of East Africa in July/August. These mechanisms include the warm and moist Congo air mass, and the East Africa low level jet (EALLJ) respectively (Ogallo, 1998).

\section{Model, data and methodology}

\section{Weather Research and Forecasting (WRF) - Environmental Modeling System (EMS)}

The Weather Research and Forecasting Environmental Modeling System (WRF-EMS) is a complete, fullphysics, state-of-the-science Numerical Weather Prediction (NWP) package that incorporates dynamical cores from both the National Center for Atmospheric Research (NCAR) Advanced Research WRF (ARW) and the National Centers for Environmental Predictions' (NCEP) Non- hydrostatic Mesoscale Model (NMM) releases into a single end-to-end forecasting system. Nearly every element of an operational NWP system has been integrated into the WRF-EMS, including the acquisition and processing of initialization data, model execution, output data processing, and file migration and archiving. Even tools for the display of forecast and simulation data are provided. Real- time forecasting operations are enhanced through the use of an automated process that integrates various fail-over options and the synchronous post processing and distribution of forecast files (Robert, 2010).

\section{Experimental design}

In this study, the model was integrated for a period of 90 days, starting at oooo UTC of 1st March to 31st May of 2011. A single domain with $14 \mathrm{~km}$ spatial resolution was configured. Initial conditions for the $14 \mathrm{~km}$ domain are derived from $6 \mathrm{~h}$ GFS Global Analyses at $1.0^{\circ} \times 1.0^{\circ}$ grids. Analysis fields, including temperature, moisture, geopotential height and wind, are interpolated to the mesoscale grids by the WRF preprocessing system (WPS). These derived fields are used as initial conditions for the present experiments. The experimental domain is $26.0-51.0^{\circ} \mathrm{E}$ and $12.0^{\circ} \mathrm{S}-12.0^{\circ} \mathrm{N}$. With a horizontal grid ranging from the Eastern Atlantic to western Indian Ocean, all domains are centered over Kenya to represent the regional-scale circulations and to resolve the complex flows in this region. For the microphysics scheme, Lin et al., 1989, scheme was used which is a sophisticated scheme that has ice, snow and graupel processes, suitable for real-data high-resolution simulations. Kain-Fritsch scheme which is a cumulus scheme was used, and it is deep and shallow convection sub-grid scheme using a mass flux approach with downdrafts and Convective Available Potential Energy (CAPE) removal time scale (Table 1).

Table 1. WRF-EMS model physics and dynamics configurations for this study

\begin{tabular}{|l|l|}
\hline Dynamics & Non-hydrostatic \\
\hline Model domain & $12.0^{\circ} \mathrm{S}-12.0^{\circ} \mathrm{N}, 26.0-51.0^{\circ} \mathrm{E}$ \\
\hline Primary Time Step & $80 \mathrm{Seconds}$ \\
\hline Vertical Layers & 45 \\
\hline Grid Dimension & $202 \times 171$ \\
\hline Grid Spacing & $14 \mathrm{~km}$ \\
\hline Top of Model Atmosphere & $50 \mathrm{mb}$ \\
\hline Map projection & $\begin{array}{l}\text { Rotated latitude and } \\
\text { longitude }\end{array}$ \\
\hline Horizontal grid system & Arakawa E-grid \\
\hline Vertical coordinate & $\begin{array}{l}\text { Terrain-following hybrid } \\
\text { (sigma-pressure) vertical } \\
\text { coordinate (38 sigma levels) }\end{array}$ \\
\hline Radiation parameterization & GFDL/GFDL \\
\hline Land surface & Noah Land Surface Model \\
\hline Surface layer Physics & Monin-Obukhov \\
\hline Cumulus Scheme & Kain-Fritsch \\
\hline PBL Scheme & Yonsei University scheme \\
\hline Microphysics Scheme & $\begin{array}{l}\text { Lin et al. scheme, for high } \\
\text { spatial resolution }\end{array}$ \\
\hline
\end{tabular}

\section{Data and methodology}

Data used in this study is the model output and observed data from 27 stations distributed throughout the country (Figure 2). The observed data was for dai- 


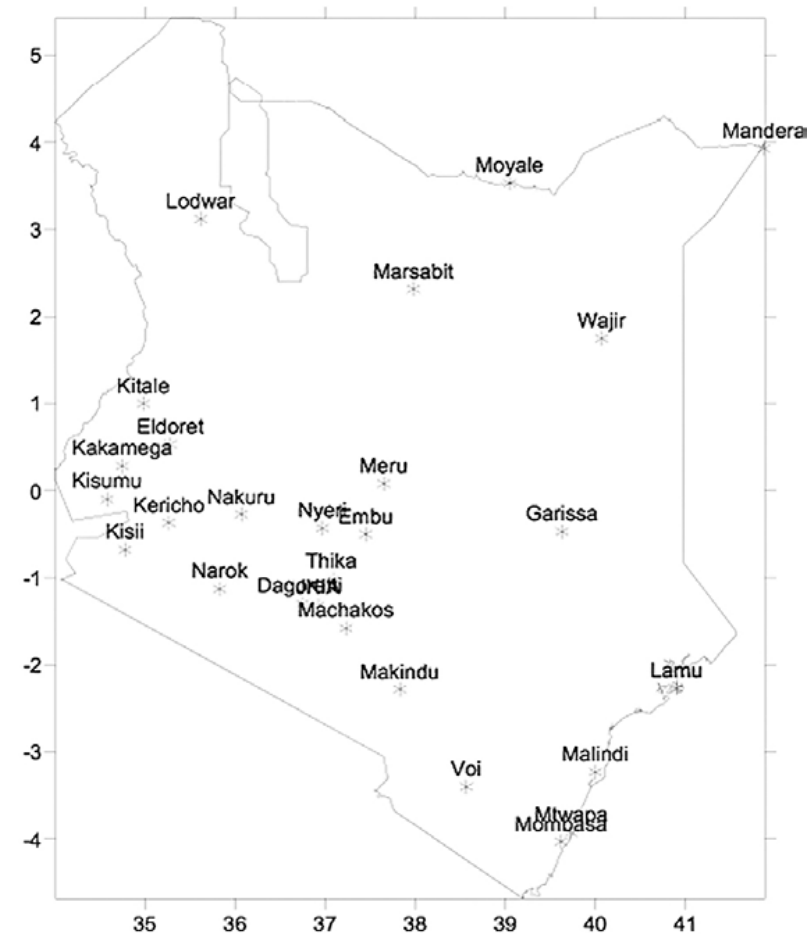

Figure 2. Study area showing the location of stations used in the study

ly data for three months (March- May) of 2011 and obtained from KMD.

The method that was used in this study includes: the analysis of Correlation Coefficient (CC), Absolute Mean Error (AME), Root Mean Square Error (RMSE), Frequency Bias Index (FBI), Equitable Threat Score (ETS), and True Skill Statistic (TSS) and Percentage correct (PC).

\section{Results}

\section{Performance of rainfall during the MAM, 2011 season}

Rainfall during this season was highly depressed and poorly distributed, both in time and space in most parts of the country (Figure 3). Figure 3 shows that most of the station received less total rainfall as compared to their long term mean. Although the seasonal rainfall was characterized by long dry spells and low rainfall values in different parts of the country especially in April, a few rainfall storms were recorded during the period. The heaviest storm of $101.5 \mathrm{~mm}, 57.3 \mathrm{~mm}$ and $76.6 \mathrm{~mm}$ was recorded at Embu station on $27^{\text {th }}$ of April, $4^{\text {th }}$ and $7^{\text {th }}$ of May, 2011 respectively. The second heaviest storm amounting to $100.6 \mathrm{~mm}$ and another one at 62.2 $\mathrm{mm}$ were recorded at Machakos station on $18^{\text {th }}$ and $19^{\text {th }}$ of March, 2011. Other storms recorded during the season include $73.9 \mathrm{~mm}$ and $91.5 \mathrm{~mm}$ recorded at Voi and Kisumu on $24^{\text {th }}$ and $31^{\text {st }}$ of March 2011 respectively, and 55.3 and $60.4 \mathrm{~mm}$ recorded at Meru and Kakamega on $21^{\text {st }}$ and $30^{\text {th }}$ of April 2011 respectively.

The rainfall during of MAM 2011 season was depressed, because of the prevailing cooler than average SSTs over the Eastern and Central Equatorial Pacific Ocean, indicating that the moderate La Niña conditions still prevailed in the Pacific. Cooler than average SSTs occurred in the south west (SW) Equatorial Indian Ocean adjacent to the East African coastline. The cooler than average SSTs over the Eastern and Central Equatorial Pacific Ocean are associated with depressed rain (Nicholson, Selato 200o). Similarly, cool south west (SW) Equatorial Indian Ocean re-

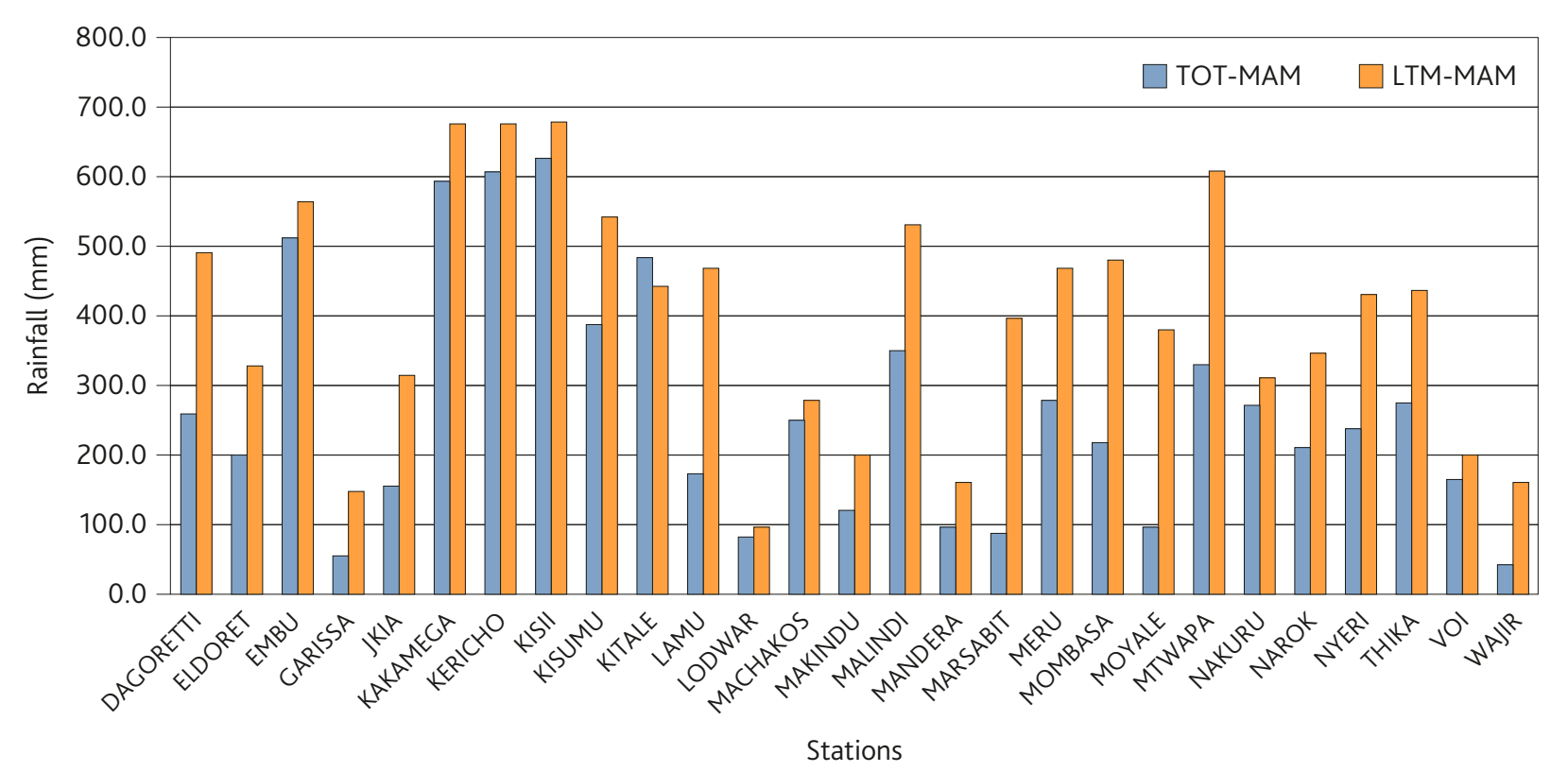

Figure 3. The rainfall performance of March-May 2011 season (TOT - Total Rainfall, LTM - Long Term Mean) 
sults in negative Indian Ocean Dipole associate with depressed rainfall over the larger East Africa (Saji, et al., 1999; Black, et al., 2003; Funk, et al., 2008). Thus, the observed cool temperature patterns in the Pacific Ocean weakened the rainfall generating mechanism that led to depressed rainfall over most parts of the country. The zonal arm of the rain-bearing system; ITCZ, was generally diffuse and mainly overlying northern Tanzania for most of the period.

\section{Results from spatial analysis}

The model did not perform well in simulation of temperature as shown in Figure 4 and 7 giving plots of the observed temperature against the forecasted. However, for rainfall, it is evident that WRF-EMS model was able reproduce the observed rainfall, except for some few stations where the model either underestimated or overestimated (Figure 5 and 6).

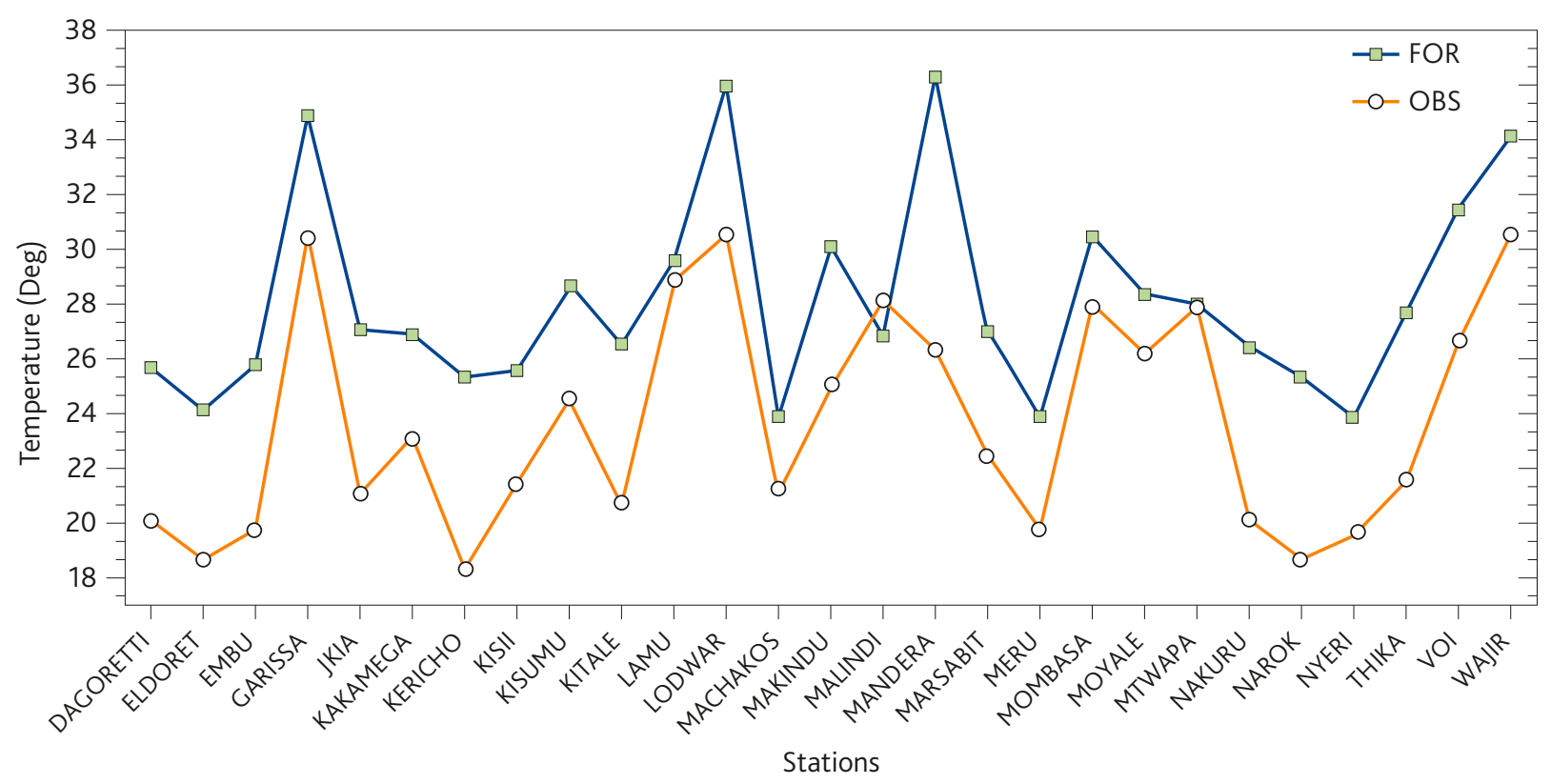

Figure 4. The observed and forecasted temperature for March-May 2011 season (FOR- Forecasted, OBS - Observed)

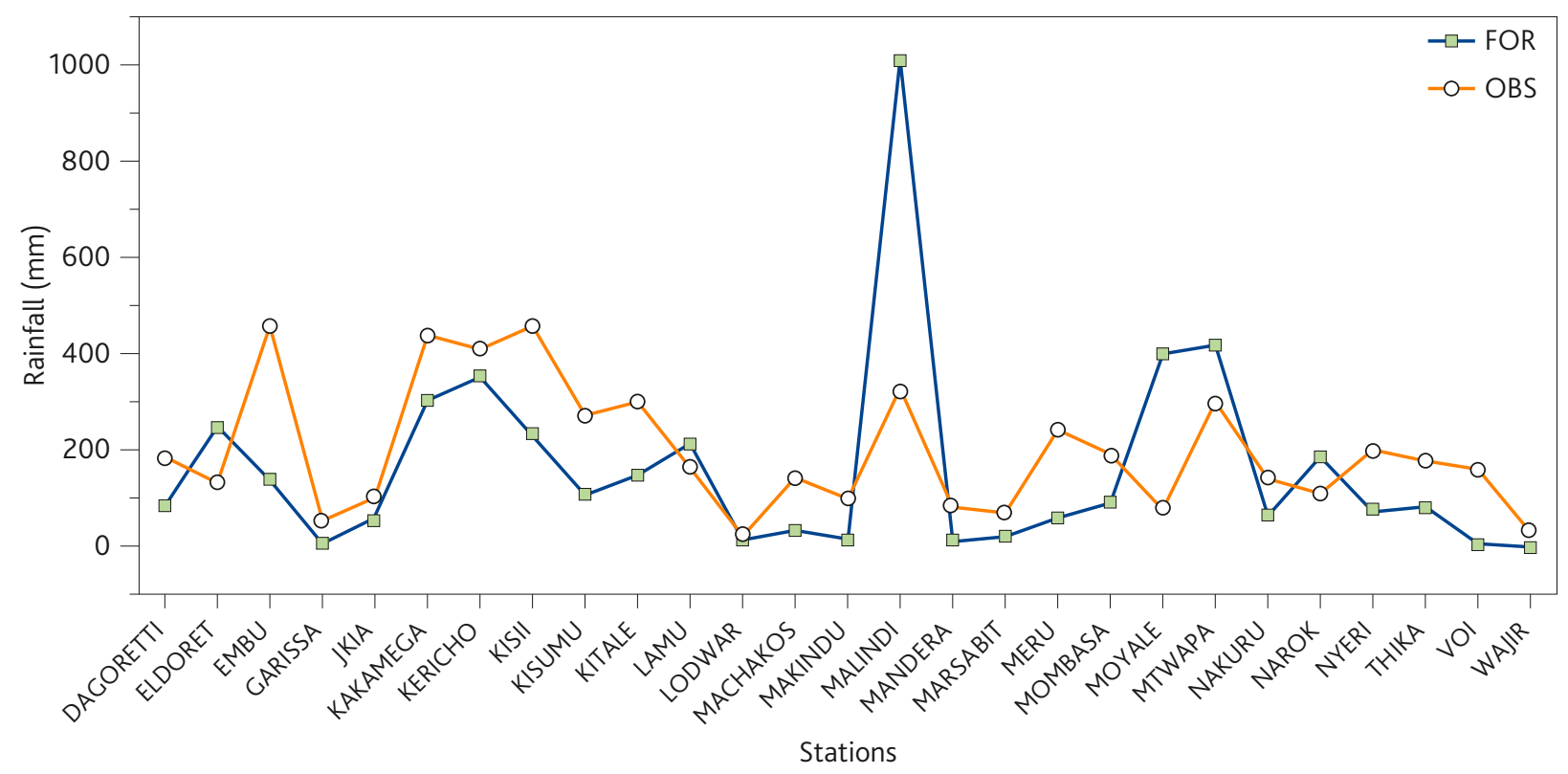

Figure 5. The observed and forecasted rainfall for the March-May 2011 season 

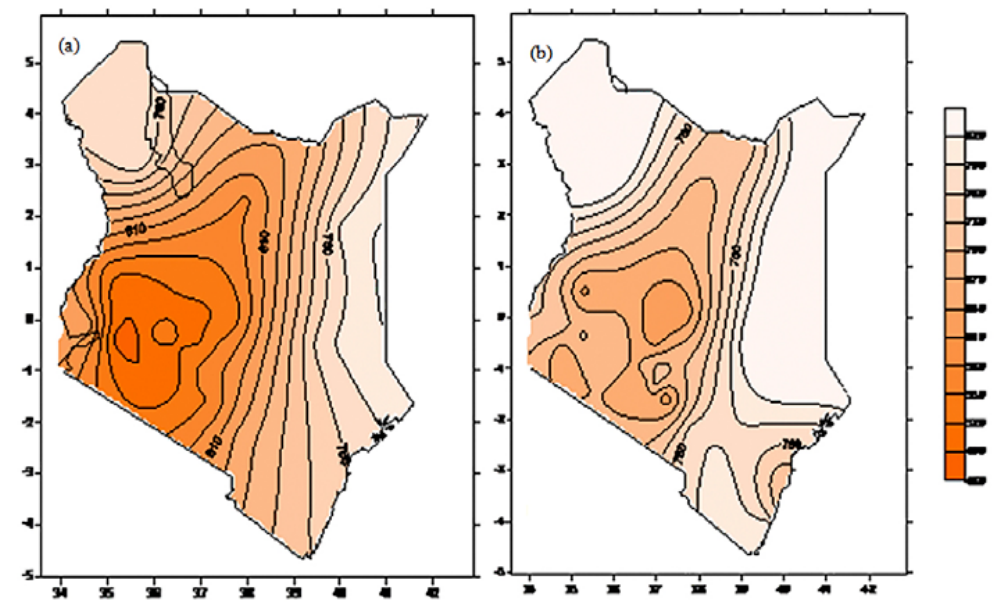

Figure 6. Spatial distribution of Rainfall for the March-May 2011 season (a) Observed Rainfall (b) Forecasted Rainfall
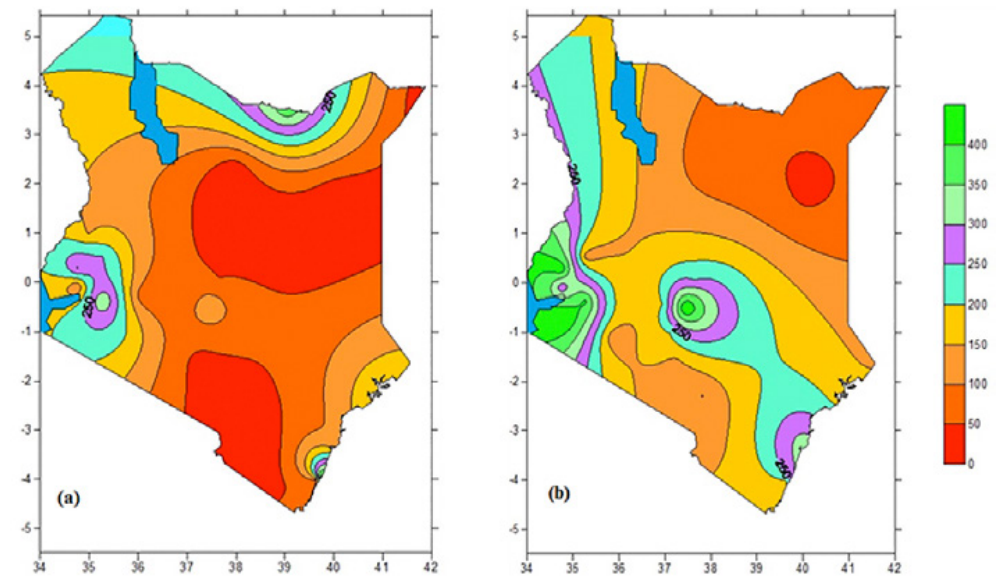

Figure 7. Spatial distribution of temperature for April 2011 (a) Observed temperature (b) Forecasted temperature

\section{Results from Assessment of Model Accuracy and Skill}

The accuracy was assessed by using RMSE, AME and CC. The skill of the model was determined using categorical statistics that include: FBI, TSS, ETS and PC.

For correlation coefficient analysis, most stations recorded high correlation between the observed and forecasted rainfall in March as compared to April.
This is because April is the peak rainfall month, and its contribution is from majorly by interaction between the meso-scale system and large scale systems.

The results for Absolute mean error (AME) and Root mean square error (RMSE) for most station had a value of less than 10, indicating that the model had a high accuracy in reproducing the observed rainfall and temperature (Table 2 and 3 ).

Table 2. Correlation Coefficient (CC), Absolute Mean Error (AME) and Root Mean Square Error (RMSE) for Rainfall for March, April and May

\begin{tabular}{|l|c|c|c|c|c|c|c|c|c|}
\hline Months & \multicolumn{3}{|c|}{ March } & \multicolumn{3}{c|}{ April } & \multicolumn{3}{c|}{ May } \\
\hline Station & CC & AME & & CC & AME & RMSE & CC & AME & RMSE \\
\hline Dagoretti & 0.69 & 2.30 & 9.37 & -0.02 & 0.58 & 5.01 & 0.22 & 4.30 & 5.37 \\
\hline Eldoret & 0.50 & 0.06 & 1.92 & 0.46 & 0.23 & 7.01 & 0.36 & 3.84 & 3.04 \\
\hline Embu & 0.62 & 0.60 & 1.57 & 0.12 & 7.31 & 20.93 & -0.04 & 4.78 & 4.24 \\
\hline Garissa & 0.00 & 0.07 & 0.27 & -0.11 & 1.12 & 3.78 & -0.05 & 0.76 & 2.03 \\
\hline JKIA & 0.91 & 0.29 & 3.12 & -0.10 & 0.35 & 2.12 & 0.16 & 1.22 & 2.39 \\
\hline Kakamega & 0.92 & 1.90 & 3.83 & 0.08 & 3.39 & 13.83 & 0.38 & 0.16 & 3.11 \\
\hline
\end{tabular}




\begin{tabular}{|c|c|c|c|c|c|c|c|c|c|}
\hline \multirow{2}{*}{$\begin{array}{l}\text { Months } \\
\text { Station }\end{array}$} & \multicolumn{3}{|c|}{ March } & \multicolumn{3}{|c|}{ April } & \multicolumn{3}{|c|}{ May } \\
\hline & $\mathrm{CC}$ & AME & & $\mathrm{CC}$ & AME & RMSE & $\mathrm{CC}$ & AME & RMSE \\
\hline Kericho & 0.54 & 1.34 & 4.43 & -0.12 & 3.87 & 9.42 & 0.27 & 0.48 & 2.88 \\
\hline Kisii & 0.48 & 0.60 & 7.79 & -0.09 & 3.74 & 18.92 & 0.43 & 4.71 & 2.96 \\
\hline Kisumu & 0.35 & 2.36 & 5.81 & 0.16 & 0.18 & 5.44 & -0.08 & 3.71 & 3.03 \\
\hline Kitale & 0.52 & 2.22 & 4.90 & 0.82 & 3.62 & 8.09 & 0.10 & 0.29 & 2.75 \\
\hline Lamu & 0.00 & 0.36 & 0.85 & 0.56 & 1.74 & 4.06 & 0.06 & 0.36 & 2.73 \\
\hline Lodwar & -0.06 & 0.18 & 0.81 & 0.11 & 0.25 & 3.38 & -0.02 & 0.03 & 1.11 \\
\hline Machakos & 0.83 & 4.08 & 12.26 & -0.02 & 0.32 & 1.11 & 0.59 & 1.17 & 1.99 \\
\hline Makindu & 0.58 & 4.06 & 12.79 & -0.06 & 0.43 & 0.99 & -0.07 & 0.14 & 0.79 \\
\hline Malindi & 0.23 & 0.57 & 4.36 & 0.22 & 14.35 & 17.89 & 0.23 & 10.35 & 4.27 \\
\hline Mandera & 0.00 & 0.01 & 0.03 & -0.08 & 1.78 & 7.03 & -0.04 & 1.16 & 2.32 \\
\hline Marsabit & 0.00 & 0.19 & 0.45 & -0.05 & 2.17 & 7.66 & -0.06 & 0.16 & 0.92 \\
\hline Meru & 0.89 & 0.56 & 2.45 & 0.05 & 5.46 & 14.17 & 0.02 & 2.13 & 2.47 \\
\hline Mombasa & -0.20 & 0.31 & 2.90 & 0.05 & 0.44 & 4.96 & 0.45 & 3.53 & 2.84 \\
\hline Moyale & 0.00 & 0.99 & 2.15 & 0.30 & 8.83 & 12.67 & 0.37 & 2.51 & 2.79 \\
\hline Mtwapa & -0.11 & 4.25 & 7.63 & -0.02 & 2.60 & 10.58 & 0.67 & 1.29 & 3.13 \\
\hline Nakuru & 0.91 & 0.90 & 3.06 & -0.10 & 0.78 & 2.28 & 0.45 & 2.17 & 2.57 \\
\hline Narok & 0.68 & 3.52 & 20.34 & 0.04 & 0.38 & 2.19 & 0.01 & 0.24 & 3.28 \\
\hline Nyeri & 0.78 & 0.10 & 1.92 & -0.01 & 2.49 & 5.89 & -0.03 & 2.06 & 2.64 \\
\hline Thika & 0.79 & 3.01 & 11.90 & 0.02 & 0.25 & 4.18 & 0.23 & 1.88 & 2.68 \\
\hline Voi & -0.05 & 3.88 & 16.54 & 0.06 & 0.72 & 3.68 & -0.06 & 1.81 & 2.55 \\
\hline Wajir & 0.00 & 0.04 & 0.16 & 0.04 & 1.28 & 3.86 & -0.06 & 0.01 & 0.46 \\
\hline
\end{tabular}

Table 3. Correlation Coefficient (CC), Absolute Mean Error (AME) and Root Mean Square Error (RMSE) for Temperature for March, April and May

\begin{tabular}{|c|c|c|c|c|c|c|c|c|c|}
\hline \multirow{2}{*}{$\begin{array}{l}\text { Months } \\
\text { Station }\end{array}$} & \multicolumn{3}{|c|}{ March } & \multicolumn{3}{|c|}{ April } & \multicolumn{3}{|c|}{ May } \\
\hline & $\mathrm{CC}$ & AME & RMSE & $\mathrm{CC}$ & AME & RMSE & $\mathrm{CC}$ & AME & RMSE \\
\hline Dagoretti & 0.12 & 6.04 & 6.15 & 0.38 & 4.97 & 5.043 & 0.10 & 3.91 & 4.13 \\
\hline Eldoret & 0.33 & 7.29 & 7.42 & -0.08 & 5.42 & 6.369 & -0.01 & 3.74 & 4.63 \\
\hline Embu & 0.14 & 4.75 & 4.94 & 0.16 & 4.15 & 4.36 & -0.18 & 9.38 & 9.44 \\
\hline Garissa & 0.02 & 4.56 & 4.88 & -0.07 & 5.11 & 8.074 & 0.36 & 4.41 & 4.56 \\
\hline JKIA & 0.28 & 6.80 & 6.93 & 0.31 & 6.15 & 6.209 & 0.41 & 5.17 & 5.25 \\
\hline Kakamega & 0.72 & 7.79 & 8.11 & 0.54 & 5.21 & 6.108 & -0.12 & 1.75 & 21.1 \\
\hline Kericho & 0.33 & 8.17 & 8.6 & -0.08 & 9.16 & 9.376 & -0.11 & 4.05 & 4.97 \\
\hline Kisii & 0.47 & 5.45 & 5.76 & 0.43 & 3.64 & 4.006 & 0.30 & 3.38 & 3.82 \\
\hline Kisumu & 0.66 & 5.78 & 6.07 & 0.40 & 3.82 & 4.214 & 0.43 & 3.11 & 3.46 \\
\hline Kitale & 0.76 & 8.41 & 8.6 & 0.18 & 6.17 & 7.028 & 0.01 & 3.09 & 3.78 \\
\hline Lamu & 0.38 & 2.09 & 1.95 & 0.21 & -0.32 & 1.333 & 0.49 & 0.27 & 0.95 \\
\hline Lodwar & 0.04 & 6.90 & 6.33 & 0.22 & 5.60 & 6.124 & 0.08 & 3.85 & 5.43 \\
\hline Machakos & 0.08 & 3.06 & 3.87 & 0.53 & 2.61 & 2.715 & 0.47 & 2.84 & 2.95 \\
\hline Makindu & 0.35 & 5.00 & 4.89 & -0.27 & 5.02 & 5.205 & 0.38 & 5.51 & 5.61 \\
\hline Malindi & 0.25 & 0.79 & 1.55 & 0.32 & 2.02 & 2.196 & 0.30 & 0.86 & 1.36 \\
\hline Mandera & 0.01 & 19.79 & 25 & -0.22 & 5.18 & 5.37 & 0.04 & 5.16 & 5.59 \\
\hline Marsabit & -0.24 & 5.26 & 5.36 & 0.44 & 4.07 & 4.243 & -0.18 & 5.33 & 5.54 \\
\hline Meru & -0.08 & 4.61 & 4.81 & 0.10 & 3.39 & 3.54 & 0.49 & 3.98 & 4.06 \\
\hline Mombasa & 0.11 & 2.72 & 2.66 & -0.02 & 2.26 & 2.604 & 0.62 & 2.56 & 2.68 \\
\hline Moyale & 0.10 & 4.65 & 4.98 & 0.14 & 1.97 & 3.71 & 0.02 & 0.03 & 1.84 \\
\hline
\end{tabular}




\begin{tabular}{|l|c|c|c|c|c|c|c|c|c|}
\hline Months & \multicolumn{3}{|c|}{ March } & \multicolumn{3}{c|}{ April } & \multicolumn{3}{c|}{ May } \\
\hline Station & CC & AME & RMSE & CC & AME & RMSE & CC & AME & RMSE \\
\hline Mtwapa & 0.14 & 0.46 & 1.28 & -0.14 & 0.24 & 1.29 & 0.20 & 0.06 & 1.04 \\
\hline Nakuru & 0.08 & 7.61 & 7.85 & 0.18 & 6.24 & 6.548 & -0.23 & 5.61 & 6.04 \\
\hline Narok & -0.10 & 8.10 & 8.51 & 0.03 & 7.14 & 7.321 & 0.00 & 5.00 & 5.3 \\
\hline Nyeri & -0.27 & 5.72 & 6.58 & 0.49 & 4.05 & 4.149 & -0.04 & 3.14 & 3.35 \\
\hline Thika & -0.22 & 6.92 & 7.32 & 0.05 & 5.82 & 5.923 & 0.27 & 5.91 & 6 \\
\hline Voi & 0.14 & 5.30 & 5.06 & -0.12 & 4.17 & 4.631 & 0.53 & 4.91 & 5.02 \\
\hline Wajir & -0.04 & 3.78 & 3.98 & -0.29 & 3.01 & 3.425 & 0.22 & 3.80 & 3.93 \\
\hline
\end{tabular}

\section{Results from measure of the skill}

The results of FBI, ETS, TSS and HR, shows that, FBI for threshold of $0.5 \mathrm{~mm} /$ day and $1 \mathrm{~mm} /$ day is close to 1 for most stations, indicating non biasness. For higher threshold of more than $3 \mathrm{~mm}$ /day the model underestimates the events while for $0.1 \mathrm{~mm} /$ day, it overstimates (Table 4).
The computation of ETS also shows that for threshold of $0.1 \mathrm{~mm}, 0.5 \mathrm{~mm}$ and $1 \mathrm{~mm} /$ day, gave the highest ETS value, as compared to the higher thresholds of 3, 5, and $10 \mathrm{~mm} /$ day. This indicates that the model has higher skill in forecasting the lower thresholds. The same results were obtained when analysing TSS as that of ETS were depicted, where the model performs better at lower thresholds than higher thresholds (Table 5 and 6).

Table 4. Frequency Bias Index (FBI) for Rainfall at different thresholds

\begin{tabular}{|c|c|c|c|c|c|c|}
\hline Rainfall (mm/day) & 0.1 & 0.5 & 1 & 3 & 5 & 10 \\
\hline Dagoretti & 1.83 & 1.38 & 1.32 & 0.47 & 0.27 & 0.17 \\
\hline Eldoret & 1.43 & 1.58 & 1.53 & 1.91 & 2.80 & 3.33 \\
\hline Embu & 1.18 & 1.03 & 0.88 & 0.82 & 0.53 & 0.17 \\
\hline Garissa & 0.75 & 0.43 & 0.60 & 0.00 & 0.00 & 0.00 \\
\hline JKIA & 2.13 & 1.43 & 1.15 & 0.86 & 0.50 & 0.33 \\
\hline Kakamega & 1.14 & 0.92 & 0.97 & 0.89 & 1.10 & 0.93 \\
\hline Kericho & 1.22 & 1.24 & 1.23 & 0.70 & 0.73 & 0.71 \\
\hline Kisii & 0.94 & 0.72 & 0.64 & 0.43 & 0.39 & 0.27 \\
\hline Kisumu & 1.17 & 0.85 & 0.71 & 0.54 & 0.38 & 0.20 \\
\hline Kitale & 1.24 & 1.19 & 1.27 & 0.90 & 0.68 & 0.90 \\
\hline Lamu & 2.12 & 2.00 & 2.11 & 1.69 & 1.33 & 1.00 \\
\hline Lodwar & 1.40 & 1.00 & 0.75 & 0.67 & 2.00 & 0.00 \\
\hline Machakos & 2.79 & 0.64 & 0.36 & 0.43 & 0.43 & 0.25 \\
\hline Makindu & 2.22 & 1.75 & 1.29 & 0.50 & 0.00 & 0.00 \\
\hline Malindi & 2.07 & 2.03 & 2.19 & 2.85 & 2.94 & 4.20 \\
\hline Mandera & 0.75 & 0.50 & 0.33 & 0.50 & 0.00 & 0.00 \\
\hline Marsabit & 0.94 & 0.38 & 0.31 & 0.29 & 0.50 & 0.00 \\
\hline Meru & 0.96 & 0.63 & 0.36 & 0.14 & 0.17 & 0.14 \\
\hline Mombasa & 1.76 & 1.42 & 0.96 & 0.29 & 0.18 & 0.33 \\
\hline Moyale & 2.24 & 2.50 & 3.55 & 4.43 & 5.20 & 7.50 \\
\hline Mtwapa & 1.66 & 1.63 & 1.87 & 1.82 & 1.75 & 2.33 \\
\hline Nakuru & 0.80 & 0.50 & 0.48 & 0.28 & 0.31 & 0.33 \\
\hline Narok & 1.94 & 1.00 & 0.73 & 0.40 & 1.00 & 0.67 \\
\hline Nyeri & 1.32 & 0.91 & 0.62 & 0.33 & 0.17 & 0.11 \\
\hline Thika & 1.63 & 1.41 & 1.05 & 0.45 & 0.50 & 0.33 \\
\hline Voi & 0.52 & 0.32 & 0.31 & 0.13 & 0.17 & 0.00 \\
\hline Wajir & 0.78 & 0.57 & 0.17 & 0.00 & 0.00 & 0.00 \\
\hline
\end{tabular}


Table 5. Equitable Threat Score for Rainfall at different thresholds

\begin{tabular}{|c|c|c|c|c|c|c|}
\hline Rainfall (mm/day) & 0.1 & 0.5 & 1 & 3 & 5 & 10 \\
\hline Dagoretti & 0.22 & 0.17 & 0.22 & 0.03 & 0.04 & -0.01 \\
\hline Eldoret & 0.24 & 0.23 & 0.29 & 0.18 & 0.14 & 0.15 \\
\hline Embu & 0.15 & 0.24 & 0.21 & 0.14 & 0.07 & 0.14 \\
\hline Garissa & 0.30 & 0.03 & -0.03 & 0.00 & 0.00 & 0.00 \\
\hline JKIA & 0.23 & 0.14 & 0.07 & 0.26 & 0.18 & 0.32 \\
\hline Kakamega & 0.24 & 0.28 & 0.23 & 0.20 & 0.20 & 0.13 \\
\hline Kericho & 0.35 & 0.28 & 0.23 & 0.12 & 0.12 & 0.22 \\
\hline Kisii & 0.25 & 0.19 & 0.13 & 0.09 & 0.03 & 0.01 \\
\hline Kisumu & 0.11 & 0.05 & 0.08 & 0.20 & 0.10 & -0.02 \\
\hline Kitale & 0.24 & 0.22 & 0.22 & 0.14 & 0.12 & -0.01 \\
\hline Lamu & 0.13 & 0.21 & 0.18 & 0.20 & 0.18 & 0.12 \\
\hline Lodwar & 0.30 & 0.12 & 0.14 & -0.02 & -0.01 & 0.00 \\
\hline Machakos & 0.11 & 0.14 & 0.03 & 0.08 & 0.08 & 0.24 \\
\hline Makindu & 0.07 & 0.03 & 0.09 & 0.18 & 0.00 & 0.00 \\
\hline Malindi & 0.14 & 0.12 & 0.15 & 0.11 & 0.12 & 0.06 \\
\hline Mandera & 0.12 & -0.03 & -0.02 & -0.02 & 0.00 & 0.00 \\
\hline Marsabit & 0.08 & 0.07 & 0.09 & -0.02 & -0.01 & 0.00 \\
\hline Meru & 0.11 & 0.04 & 0.07 & 0.04 & 0.05 & 0.13 \\
\hline Mombasa & 0.09 & 0.13 & 0.17 & 0.10 & -0.02 & -0.02 \\
\hline Moyale & 0.07 & 0.04 & 0.03 & 0.07 & 0.05 & 0.11 \\
\hline Mtwapa & 0.09 & 0.07 & 0.04 & 0.09 & 0.14 & -0.01 \\
\hline Nakuru & 0.23 & 0.09 & 0.11 & 0.10 & 0.17 & 0.32 \\
\hline Narok & 0.19 & 0.20 & 0.29 & 0.13 & 0.22 & 0.23 \\
\hline Nyeri & 0.11 & 0.16 & 0.03 & 0.13 & -0.02 & -0.01 \\
\hline Thika & 0.29 & 0.25 & 0.17 & 0.10 & 0.16 & 0.12 \\
\hline Voi & 0.04 & 0.02 & 0.02 & -0.01 & -0.01 & 0.00 \\
\hline Wajir & 0.10 & 0.07 & 0.06 & 0.00 & 0.00 & 0.00 \\
\hline
\end{tabular}

The hit rate was above 50\%. These results closely agree with the findings by Pohl et al. (2011) that tested the capability of WRF in simulating the atmospheric water cycle over Equatorial East Africa. According to persist- ing biases were recorded in too wet conditions such as Indian Ocean and too dry over eastern Kenya. However, in most experiments, several configurations simulated the regional climate with reasonable accuracy.

Table 6. True skill statistics for Rainfall at different thresholds

\begin{tabular}{|l|c|c|c|c|c|c|}
\hline Rainfall (mm/day) & 0.1 & 0.5 & 1 & 3 & 5 & 10 \\
\hline Dagoretti & 0.45 & 0.32 & 0.40 & 0.05 & 0.06 & -0.01 \\
\hline Eldoret & 0.43 & 0.45 & 0.54 & 0.42 & 0.44 & 0.56 \\
\hline Embu & 0.26 & 0.39 & 0.34 & 0.24 & 0.10 & 0.17 \\
\hline Garissa & 0.05 & 0.04 & -0.04 & 0.00 & 0.00 & 0.00 \\
\hline JKIA & 0.53 & 0.29 & 0.13 & 0.38 & 0.24 & 0.33 \\
\hline Kakamega & 0.39 & 0.44 & 0.38 & 0.32 & 0.35 & 0.23 \\
\hline Kericho & 0.49 & 0.43 & 0.37 & 0.21 & 0.20 & 0.33 \\
\hline Kisii & 0.42 & 0.36 & 0.25 & 0.17 & 0.06 & 0.02 \\
\hline Kisumu & 0.21 & 0.09 & 0.14 & 0.30 & 0.14 & -0.03 \\
\hline Kitale & 0.39 & 0.37 & 0.39 & 0.24 & 0.19 & -0.02 \\
\hline
\end{tabular}




\begin{tabular}{|l|c|c|c|c|c|c|}
\hline Rainfall (mm/day) & 0.1 & 0.5 & 1 & 3 & 5 & 10 \\
\hline Lamu & 0.29 & 0.46 & 0.41 & 0.42 & 0.34 & 0.21 \\
\hline Lodwar & 0.54 & 0.21 & 0.22 & -0.03 & -0.03 & 0.00 \\
\hline Machakos & 0.33 & 0.21 & 0.04 & 0.11 & 0.11 & 0.25 \\
\hline Makindu & 0.20 & 0.07 & 0.18 & 0.24 & 0.00 & 0.00 \\
\hline Malindi & 0.29 & 0.26 & 0.33 & 0.33 & 0.35 & 0.28 \\
\hline Mandera & 0.19 & -0.04 & -0.03 & -0.03 & 0.00 & 0.00 \\
\hline Marsabit & 0.14 & 0.11 & 0.12 & -0.03 & -0.01 & 0.00 \\
\hline Meru & 0.20 & 0.07 & 0.11 & 0.06 & 0.07 & 0.14 \\
\hline Mombasa & 0.18 & 0.25 & 0.28 & 0.14 & -0.03 & -0.03 \\
\hline Moyale & 0.19 & 0.12 & 0.14 & 0.33 & 0.27 & 0.82 \\
\hline Mtwapa & 0.16 & 0.13 & 0.09 & 0.21 & 0.32 & -0.02 \\
\hline Nakuru & 0.36 & 0.15 & 0.16 & 0.13 & 0.21 & 0.33 \\
\hline Narok & 0.43 & 0.33 & 0.40 & 0.17 & 0.36 & 0.32 \\
\hline Nyeri & 0.19 & 0.27 & 0.06 & 0.17 & -0.03 & -0.02 \\
\hline Thika & 0.52 & 0.44 & 0.30 & 0.13 & 0.22 & 0.15 \\
\hline Voi & 0.06 & 0.03 & 0.03 & -0.01 & -0.01 & 0.00 \\
\hline Wajir & 0.02 & 0.10 & 0.17 & 0.00 & 0.00 & 0.00 \\
\hline
\end{tabular}

\section{Discussion and conclusion}

The March to May, 2011 seasonal rainfall was highly depressed and poorly distributed, both in time and space over most parts of the country. The WRF-EMS model was able to reproduce the general spatial distribution pattern of the observed rainfall and temperature. However, during the days with storms, the model displaced the location of the storm and it under estimated the rainfall amount, while overestimating in areas with low rainfall. The model simulated fairly well the spatial distribution of temperature, though there were over estimation over a few location. The deficiency in simulation of rainfall, also affect the temperature, since temperature is dependent among other things on latent heat release.

Generally, the model performs well in forecasting both rainfall and temperature over Kenya. However, the accuracy in forecasting specified rainfall and temperature thresholds decrease with increase in threshold amount/level. WRF-EMS may be used with confidence for predictions of rainfall and temperature in most of the study area. It may however fail to predict the occurrence of storm, especially over the coastal and western parts of the coountry. Therefore, there is need to improve the model's performance over the domain area, through reviewing the parameterization of small scale physical processes.

\section{Acknowledgement}

The authors would like to express their special appreciation to Kenya Meteorological Department for provison of the data used in this study.

\section{References}

Anyah, R.O., Semazzi, F.H.M. 2006. Climate variability over the Greater Horn of Africa based on NCAR AGCM ensemble. Theoretical and Applied Climatology 86, 39-62. http://doi.org/10.1007/s00704-0050203-7

Asnani, G.C Kinuthia, J.H. 1979. Diurnal variation of Precipitation in East Africa. East Africa Institute for Meteorological Training and Research. Res. Rep. No. 8/79.

Black, E., Slingo, J.M., Sperber, K.R. 2003. An observational study of the relationship between excessively strong short rains in coastal East Africa and Indian Ocean SST. Monthly Weather Review 131, 74-94. http://doi.org/10.1175/1520-0493(2003)131<0074:AO SOTR>2.0.CO;2

Camberlin, P., Philippon, N. 2002. The East African March - May Rainy Season: Associated Atmospheric Dynamics and Predictability over the 196897 Period. Journal of Climate 15, 1002-1019. http:// doi.org/10.1175/1520-0442

Cherubini, T., Ghelli. A., Lalaurette, F. 2002. Verification of precipitation forecasts over the Alpine region using a high-density observing network. Weather Forecast 17, 238-249.

Funk, C., Dettinger, M.D., Michaelsen, J.C., Verdin, J.P., Brown, M.E., Barlow, M., Hoell, A. 2008. Warming of the Indian Ocean threatens eastern and southern African food security but could be mitigated by agricultural development. Proceedings of National Academy of Sciences USA 105,11081-11086.

Gitutu, J.M. 2006. A Comparative Verification of Precipitation Forecasts for Selected Numerical Weath- 
er Prediction Models over Kenya. PhD. Thesis, University of Nairobi, Kenya.

Indeje, M. 1994. A numerical study of the effects of the roughness length on the mesoscale flow patterns over Kenya. PhD. Thesis, University of Nairobi, Kenya.

Indeje, M., Semazzi, F.H.M., Xie, L., Ogallo, L.J. 2001. Mechanistic model simulations of the East African climate using NCAR regional climate model: Influence of large-scale orography on the Turkana lowlevel jet. Journal of Climate 14, 2710-2724. http://doi. org/10.1175/1520-0442(2001)014<2710:MMSOTE $>2$. o.CO;2

Lilly, D.K. 1990. Numerical prediction of thunderstorms - has its time come? Quarterly Journal of Royal Meteorological Society 116, 779-798.

Lin, Y.L., Farley, R.D., Orville, H.D. 1983. Bulk parameterization of the snow field in a cloud model. Journal of Climate Applied Meteorology 22, 1065-1092.

Litta, J., Mohantya, U., Bhanb, S. 2010. Numerical Simulation of a tornado over Ludhiana (India) using WRF-NM model. Meteorological Applications $17,64-75$.

Mukabana, J.R. 1992. Numerical simulation of the influence of large-scale Monsoon flow on weather patterns over Kenya using a three-dimensional limited area model. PhD. Thesis, University of Nairobi, Kenya

Murphy, J.M., Sexton, D.M.H., Barnett, D.N., Jones, G.S., Webb, M.J., Collins, M., Stainforth, D.A. 2004. Quantification of modelling uncertainties in a large ensemble of climate change simulations. $\mathrm{Na}$ ture 429, 768-772.

Mutai, C.C., Ward, M.N. 200o. East African rainfall and the tropical circulation/convection on intraseasonal to interannual timescales. Journal of Climate 13, 3915-3939. http://doi.org/10.1175/15200442(2000)013<3915:EARATT>2.0.CO;2

Muthama, N.J., Masieyi, W.B., Okoola, R.E., Opere, A.O., Mukabana, J.R., Nyakwada, W., Aura, S., Chanzu, B.A., Manene, M.M. 2012. Survey on the Utilization of Weather Information and Products for Selected Districts in Kenya. Journal of Meteorology and Related Sciences 6, 51-58.
Nicholson, S.E., Selato, J.C. 200o. The influence of La Nina on African Rainfall. International Journal of Climatology 20, 1761-1776.

Ogallo, L.A. 1989. The spatial and temporal Patterns of East African- rainfall derived from principal component analysis. International Journal of Climatology 9, 145-167.

Ogallo, L.J. 1988. Relationship between Seasonal Rainfall in East Africa and Southern Oscillation. Journal of Climatology 8, 34-43.

Ogallo, L.J. 1989. The spatial and temporal patterns of the East African seasonal rainfall derived from principal component analysis. International Journal of Climatology 9, 145-165.

Ogwang, B.A., Chen, H., Tan, G., Ongoma, V., Ntwali, D. 2015. Diagnosis of East African climate and the circulation mechanisms associated with extreme wet and dry events: a study based on RegCM4. Arabian Journal of Geosciences 8, 10255-10265. DOI 10.1007/s12517-015-1949-6

Pohl, B., Cretat, J., Camberlin, P. 2011. Testing WRF capability in simulating the atmospheric water cycle over Equatorial East Africa. Climate Dynamics 37, 1357-1379. DOI 10.1007/soo382-011-1024-2

Saji, N.H., Goswami, B.N., Vinayachandran, P.N., Yamagata, T. 1999. A dipole mode in the tropical Indian Ocean. Nature 401, 360-363. http://doi. org/10.1038/43854

Sakwa, V.N. 2006. Assessment of the Skill of the High Resolution Regional Model in the Simulation of Airflow and Rainfall over East Africa. PhD. Thesis, University of Nairobi, Kenya

Taylor, P.K. 2001. Intercomparison and validation of ocean-atmosphere energy flux fields. Joint WCRP/ SCOR Working Group on Air-Sea Fluxes Final Rep., WCRP-112, WMO/TD-No. 1036, 306.

Yang, W., Seager, R., Cane, M.A., Lyon, B. 2015. The Annual Cycle of the East African Precipitation. Journal of Climate 28, 2385-2404. http://doi.org/10.1175/ JCLI-D-14-00484.1

Zhang, X. 2007. Adapting the weather research and forecasting model for the simulation of regional climate in East Africa. PhD. Thesis, North Carolina State University 